\title{
Humiliation and the Inertia Effect: Implications for Understanding Violence and Compromise in Intractable Intergroup Conflicts
}

\author{
Jeremy Ginges ${ }^{\mathrm{a}, *}$ and Scott Atran ${ }^{\mathrm{b}, \mathrm{d}, \mathrm{d}}$ \\ ${ }^{a}$ Department of Psychology, New School for Social Research, 65 Fifth Avenue, \\ New York, NY 10003, USA \\ ${ }^{\mathrm{b}}$ CNRS - Institut Jean Nicod, Paris, France \\ c John Jay College of Criminal Justice, New York, NY, USA \\ ${ }^{d}$ University of Michigan, Ann Arbor, MI, USA \\ * Corresponding author, e-mail: gingesj@newschool.edu
}

\begin{abstract}
We investigated the influence of humiliation on inter-group conflict in three studies of Palestinians living in the West Bank and Gaza. We demonstrate that experienced humiliation produces an inertia effect; a tendency towards inaction that suppresses rebellious or violent action but which paradoxically also suppresses support for acts of inter-group compromise. In Study 1, Palestinians who felt more humiliated by the Israeli occupation were less likely to support suicide attacks against Israelis. In Study 2, priming Palestinians with a humiliating experience caused fewer expressions of joy when subsequently hearing about suicide attacks. In Study 3, Palestinians who felt more humiliated by peace deals were less likely to support those deals, while Israeli symbolic compromises that decreased feelings of humiliation increased support for the same deals. While the experience of humiliation does not seem to contribute to political violence, it does seem to suppress support for conflict resolution.
\end{abstract}

Keywords

Humiliation, political, violence, conflict, terrorism

\begin{abstract}
"They [the United States] have attacked our brothers in Palestine as they have attacked Arabs and Muslims elsewhere. The blood of Muslims is shed. It has become too much.... We are only looked upon as sheep, and we are very humiliated." Osama Bin Laden (cited by Wright, 2006, p. 150)
\end{abstract}

The humiliation and subjugation of other groups is a terrible feature of human political life. As the above quote indicates, humiliation is often thought to be a significant cause of inter-group violence. Humiliation has been used to help explain the aggression of Nazi Germany following the Versailles treaty (e.g., 
Lindner, 2006) and the violence of non-state actors, such as suicide bombers (Jurgensmeyer, 2000; Atran, 2003; Stern, 2003; Moghadam, 2006; Newman, 2006; Sen, 2006; Bergen and Lind, 2007). The idea that humiliation leads to reactive violence has strong roots in psychoanalytic theory (Steinberg, 1991) and has substantial anecdotal support (Hassan, 2007). For example, in interviews that we and others have conducted, members of different militant groups often attribute their own violent acts to personal or collective humiliation experienced at the hands of their oppressors (Atran and Stern, 2005; Fontan, 2006). Despite the importance of the topic, empirical tests of the role of humiliation in influencing violent intractable conflict are rare (Victoroff, 2005). The research discussed in this paper was intended to fill this gap.

Any discussion of humiliation is limited by the paucity of empirical investigation into its qualities. A first step is to examine cross cultural appearances of the word humiliation and attend to their literal meanings. "Humiliation" is derived from the Latin humiliatus (made to lose pride or self-respect) from humilis (low, humble) and from humus (dirt, earth). As an indication of its importance, we have yet to find a language where there is no literal translation of the English word humiliation. Words for humiliation in other languages such as, Chinese, Hindi, Urdu, Arabic, Russian, Polish, German and Hungarian contain these same connotations (relative lowering of social status, pride and self-respect, being lowered to the dirt). This literal description of humiliation resonates in speculations regarding the characteristics of humiliation within the psychological literature. Humiliation is thought to belong to the family of self conscious (Tangney and Fischer, 1995) and moral (Margarit, 2002) emotions such as shame and pride. Humiliation is generally considered to be a feeling of being unjustly demeaned, devalued or subjugated by another's actions in a social context (Hartling and Luchetta, 1999; Lindner, 2002) in a manner that evokes "... a deep dysphoric feeling of inferiority" (Coleman et al., 2007). The constant in this discussion is that being humiliated is associated with a loss of power in a public context. In this paper we propose that an outcome of this loss of power is an inertia effect, a tendency towards inaction that, in contrast to assumptions discussed at the outset of the paper, actually suppresses rebellious or violent action but which also suppresses mutuallybeneficial compromises to inter-group conflicts.

Leaders of violent insurgent groups from Red Army Brigades to Fatah and the Lehi have long argued that passivism born by humiliation decreases the prospects of popular rebellion (Ginges, 1997) unless the oppressed are "illuminated by violence" (Fanon, 1967). As many insurgent leaders supposed, power is positively associated with the agency (Keltner et al., 2003) necessary to planned acts of rebellion, violent or otherwise. Positions and perceptions of 
being in relatively high power is negatively associated with perspective taking (Fiske, 1993; Galinsky et al., 2006) that might inhibit violence and is positively associated with a variety of aggressive behaviors (Keltner et al., 2001; Studd, 1996). In contrast, positions or perceptions of being in relatively low power is associated with inhibited behaviors (Ellyson and Dovidio, 1985; Moreland and Levine, 1989; Keltner et al., 1998; Holtgraves and Lasky, 1999).

While it should be noted that insults can cause violent reactions, particularly in so-called honor based societies (Nisbett and Cohen, 1996), the attempt to insult or humiliate is not equivalent to the psychological experience of being insulted or humiliated. In fact, the extent to which insult leads to violent reactions is moderated by narcissism which is positively associated with power (Campbell et al., 2007). People who score low on narcissism scales are no more likely to be aggressive in response to insult than to praise; high narcissism seems necessary for insult to lead to aggression (Bushman and Baumeister, 1998). Because narcissists show high agentic self-esteem (Campbell et al., 2007) and are less likely than others to internalize insults (Campbell et al., 2004), these results imply that it is those who are least likely to feel humiliated by an insult who are most likely to respond with aggression. In short, there is reason to doubt whether humiliating people and thus degrading their power is likely to cause violent reaction. Rather, it appears likely that humiliation may actually suppress violence. Our primary goal in the research we described here was to evaluate the relationship between humiliation and political violence.

We propose that the inertia effect that follows humiliation has a second consequence relevant to understanding inter-group conflict. Humiliation, ironically, may also suppress support for mutually beneficial compromise to intergroup conflicts. People will often irrationally resist compromising over values they deem sacred such as "holy" land (Tetlock, 2003; Ginges et al., 2007). We hypothesized that people experience a request to compromise a "sacred value" as humiliating, an experience that suppresses willingness to act in support for mutually beneficial peace deals. This may lead to intractable conflict, because compromising over such values is often a key component in peace deals. If humiliation suppresses support for political compromise, it follows that efforts to decrease humiliation will increase the prospects of support for the same compromise. Previously we have shown that violent opposition to such compromises can be reduced if the other party makes simultaneous symbolic compromises over one of their own sacred values (Ginges et al., 2007; Atran, Axelrod and Davis, 2007). Here we investigated whether such symbolic compromises might reduce the inertia effect of humiliation and in doing so increase popular support for difficult but beneficial political compromise. 


\section{Overview of Research}

We investigated these predictions in two large-scale surveys of Muslim Palestinians residing in the West Bank and Gaza. The first survey was of a representative sample carried out in December 2005. The second survey was of a sample of university students carried out in May 2006. We chose this population for three reasons. First, Palestinian society is an honor based society (PHRMG, 2002). Some emerging theories of a positive relationship between humiliation and political violence argue that humiliation is most likely to result in aggression in societies strongly concerned with issues of honor (e.g., Coleman et al., 2007). Thus testing our claim of a negative relationship between humiliation and violence in this population is particularly appropriate. Second, investigating this population allowed us to examine issues directly relevant to the Palestinian-Israeli conflict, one consistently rated as one of the greatest threats to world peace (Pew Research Center, 2006). Third, humiliation has frequently been used to explain the use of suicide attacks amongst Palestinians (e.g., Stern, 2003). Below we describe three studies. The first two deal with the relationship between humiliation and political violence. Study 3 then examines the hypothesized relationship between humiliation and conflict intractability.

\section{Study 1: Humiliation Is Negatively Correlated with Support for Political Violence}

In our first study, we investigated whether Palestinian support for suicide attacks against Israelis could be predicted by the degree to which Palestinians experienced humiliation caused by the Israeli occupation of the West Bank and Gaza. In November 2005 we surveyed a nationally representative sample of 1264 Muslim Palestinian adults living in the West Bank. The survey was conducted by the Palestinian Center for Policy and Survey Research (PCPSR), which conducted face-to-face in the homes of participants. For a description of survey methodology see http://pcpsr.org. The refusal rate was $<5 \%$. All materials were piloted to ensure transparency of meaning. The measures described in this paper were integrated within a larger survey of political and social attitudes and occurred in the first part of that survey.

\section{Measures}

Our predictor variable was experienced humiliation as a consequence of the Israeli occupation. In previous studies we have found that asking this popula- 
tion to rate the extent to which they feel an emotion along a semantic or numeric scale measure produces low variance. A more effective measure is to ask participants to nominate out of a list of emotion words the word which best, and the word which second best, describes how they are feeling. In this study we asked participants: "Which of the following feelings/emotions come to mind when thinking about..." and we then listed seven potentially humiliating aspects of the Israeli occupation. Participants were asked to indicate their first and second emotional response to each aspect from the following list: sadness, dignity, humiliation, pride, oppression, justice, insult, fear, joy, anger, freedom, revenge, powerful, frustration, powerless. Table 1 lists the events we asked about and shows the percentage of our sample who responded with humiliation in each case. We constructed humiliation scores for each event by assigning a value of " 2 " if participants chose humiliation first, " 1 " if humiliation was chosen second, and a score of " 0 " if humiliation was not chosen. We then created a general humiliation scale by summing scores on individual humiliation scales. Scores on this last scale, "humiliation", ranged from 0 to $10($ mean $=2.517, \mathrm{SD}=1.904)$.

Table 1

Humiliation of Palestinians. Percentage of Palestinians who reported feeling humiliated (as their first or second response) when thinking about aspects of the Israeli occupation of the West Bank and Gaza

\begin{tabular}{lcr}
\hline & $\begin{array}{c}\text { First } \\
\text { response }\end{array}$ & $\begin{array}{c}\text { Second } \\
\text { response }\end{array}$ \\
\hline People stand in line at checkpoints & $47 \%$ & $17 \%$ \\
The number of settlers increases all the time & $6 \%$ & $5 \%$ \\
Palestinian farmers are unable to reach their land & $15 \%$ & $10 \%$ \\
The wall encircles Palestinian land & $11 \%$ & $12 \%$ \\
Unemployment increases due to Israeli closures & $9 \%$ & $9 \%$ \\
Assassination of Palestinian activists & $2 \%$ & $3 \%$ \\
Demolition of Palestinian homes & $6 \%$ & $6 \%$ \\
\hline
\end{tabular}

We used three measures of support for suicide attacks against Israeli citizens. In the first measure, participants were asked to nominate their emotional responses to hearing of suicide attacks using the same list of possible emotional responses as above. The most common emotional response was "joy" (50\% first response, $12 \%$ second). The other common positive emotional response was "pride" 
(12\% first response, 13\% second). For this measure, expression of "joy" was the criterion for a positive emotional response to suicide attacks, although we also examined "pride". In the second measure, participants were asked what, in their opinion was the position of Islam regarding suicide attacks "that target civilians such as the bombing of a bus in an Israeli city?" Responses were coded on a "4" (certainly support) to "1" (certainly oppose) semantic scale (Mean = $2.84, \mathrm{SD}=0.91$ ). In the third measure, participants were asked what, in their opinion, was the position of Islam regarding the suicide bomber who kills "himself with the aim of killing his enemies as some Palestinians do. Does Islam certainly allow (coded "4"), allow (coded "3"), not allow (coded "2"), or certainly not allow (coded "1") such action?" (mean $=3.04, \mathrm{SD}=0.79$ ). Expressions of joy when hearing about suicide bombing attacks were positively related to a belief that Islam supported suicide attacks in general $\left(r_{\text {Spearman }}=0.21, P<\right.$ $0.001)$ and allowed the acts of suicide bombers $\left(r_{\text {Spearman }}=0.2, P<0.001\right)$. Pride was more weakly correlated with these same two dependent variables $\left(r_{\text {spearman }}=\right.$ $\left.0.11, P<0.001 ; \mathrm{r}_{\text {Spearman }}=0.12, P<0.001\right)$.

Results

(1) Humiliation was negatively related to the expression of "joy" when hearing of a suicide attack. Taking each potentially humiliating event separately, expressions of humiliation when thinking about checkpoints, the number of settlers growing and demolitions was negatively related to expressions of "joy at $P<0.05$. An unreliable trend in the same direction was found for the other four events: farmers being unable to reach their land, the wall, loss of jobs, and assassinations. Looking at the overall humiliation score: a logistic regression showed that each increase in the humiliation score reduced the likelihood of a person expressing joy when hearing about suicide bombings by a multiplicative factor of 0.935 (Wald $=4.951,95 \%$ SI for Odds Ratio $=0.882-0.992$, $P=0.026)$. This negative effect of humiliation on support for suicide bombings is clearly seen when we compare people who scored high on the humiliation scale (defined by scoring at least 1 standard deviation above the mean) with others. Compared to other Palestinians, the predicted odds of first expressing "joy" when hearing of suicide attacks was lower by a factor of 0.598 for Palestinians who scored high on humiliation (Wald $=9.279,95 \%$ CI on Odds Ratio $=0.429-0.832, P=0.002)$. When controlling for gender, age, refugee status (refugee or not), education level, and whether participants opposition to compromise over the right of return was a "sacred value", participants who expressed "joy" when hearing of suicide attacks still were less likely to score high on the humiliation scale (Wald $=7.208,95 \%$ CI on Odds Ratio $=$ 
$0.443-0.881, P=0.007)$. Humiliation was unrelated to expressions of pride at bombing attacks (all $P>0.4$ ).

(2) Humiliation was also negatively related to the second dependent variable: multiple regression analysis found that Palestinians who scored high on humiliation scale scored lower on the scale measuring the belief that Islam supports the use of suicide attacks $(B=-0.183, \mathrm{SE}=.08, t=-2.271, P=$ $0.023)$ This relationship was stable when we included the control variables listed above $(P=0.050)$.

(3) Humiliation was also negatively related to the third dependent variable (the belief that Islam allowed the actions of the suicide bomber), although this finding was not statistically reliable $(P=0.246)$, possibly due to the lower variance on this item.

\section{Summary}

Study 1 found the predicted inertia effect. Although the size of the negative effect was small to moderate, it ran counter in each case to the notion that humiliation leads to reactive political aggression. Humiliation as a product of salient negative aspects of the Israeli occupation was never positively correlated with support for suicide attacks. Instead it tended to negatively predict support for violence.

\section{Study 2: Experiencing Humiliation Decreases Support for Suicide Attacks}

Perhaps the strongest measure of support for an act political violence is the expression of joy when hearing about the act. In the second study, we examined the inertia effect of humiliation further using a cognitive priming experiment. Using a between subjects design we manipulated feelings of humiliation caused by the Israeli occupation and examined the effect on expressions of joy when hearing about suicide attacks. The experiment was embedded in a survey of 720 Palestinian students, half of whom identified with Hamas or Palestinian Islamic Jihad (PIJ). This is a particularly relevant sample as the majority of Palestinian suicide attackers have been student members of Hamas or PIJ. This survey was run by PCPSR in May 2006, and comprised face to face individual interviews with participants across 14 campuses in the West Bank and Gaza. The study had equal numbers of men and women and the refusal rate was $<5 \%$. We were interested in whether priming participants by reminding them of the most humiliating aspect of the Israeli occupation (standing in line at Israeli checkpoints, as found in Study 1) would influence the likelihood of 
them reporting feeling "joy" when hearing of bombing attacks. All participants were asked to report their emotional reactions to two of the events measured in Study 1: standing in line at checkpoints and hearing about suicide attacks. The wording of the items and the list of possible emotional responses were identical to those used in Study 1. We randomly manipulated the order of items: half of our participants were reminded of checkpoints before being asked about the suicide attacks, while the other half answered the question about suicide attacks first.

We predicted that the effect of question order would be moderated by whether participants reported experiencing humiliation when reminded of people standing in line at checkpoints. We expected that for participants who reported humiliation when thinking about checkpoints, the checkpoint-suicide attack order would lead to fewer reports of "joy" when hearing about suicide attacks compared to the suicide attack-checkpoint order. That is, reminding participants of a humiliating event would reduce positive emotional responses to suicide attacks. In contrast, we expected that participants who did not report experiencing humiliation when reminded of suicide attacks would show no effect of question order or the opposite effect.

Results

The most common emotional response to standing in line at a checkpoint was humiliation $(66 \%)$. The next most common response was insult $(24 \%)$ followed by oppression (20\%). The most common initial response to thinking of suicide attacks was "joy" (41\%). Other common responses were "pride" $(30 \%)$, and "sadness" (8\%). Because "joy" was again the most prevalent response and because it showed the strongest relationship to cognitive measures of support for suicide attacks in Study 1, joy was our primary dependent variable, although we ran identical tests on pride.

As expected, the influence of question order was moderated by whether or not participants reported feeling humiliated when standing in line at checkpoints: Wald $=4.885, \mathrm{OR}=0.485(95 \% \mathrm{CI}=0.255-0.921), P=0.027$. Participants who reported humiliation when thinking about checkpoints were less likely, by a factor of 0.589 (Wald $=6.903,95 \%$ CI for Odds Ratio $=$ $0.407-0.871, P=0.009$ ) to report feeling "joy" as their first emotional response to hearing about a suicide attack if they had been previously reminded of standing in line at checkpoints. In contrast, participants who did not report experiencing humiliation when standing in line at checkpoints were not influenced by question order $(P=0.425)$. The experimental manipulation did not influence feelings of "pride" when hearing of suicide attacks (not significant). 
Summary

Reminding participants of an event that was experienced as humiliating reduced reports of joy when hearing about suicide attacks. This priming experiment replicates the correlational results in Study 1 where humiliation was negatively related to support for political violence.

\section{Study 3: Humiliation and Support for Political Compromise}

In Study 3 we tested two propositions regarding the inertia effect of humiliation: first, that humiliation would also decrease support for rational compromises to political conflict (in Study 3a); and second, that adding instrumental benefits to compromise would not reduce the inertia effect but rather that symbolic actions by an out-group (such as recognition of wrongdoing and apologies) would decrease feelings of humiliation and thus increase support for political compromise (in Study 3b).

These scenarios were integrated in the survey of Palestinian students described in Study 2. Participants all responded to peace deals in two scenarios (see Ginges et al. (2007) for a full description of each deal) and were randomly assigned, using a between subjects design, to a taboo, taboo+, or symbolic deal. In Scenario 1 , the peace deal involved Palestinian recognition of the legitimacy of the Jewish state in return for: (i) their own state in 99\% of the West Bank and Gaza (taboo deal), (ii) their own state plus financial compensation (taboo+ deal), or (iii) their own state plus Israeli recognition of the legitimacy of the Palestinian state and an Israeli apology to Palestinians (symbolic deal). In Scenario 2, the peace deal involved Palestinians renouncing sovereignty over East Jerusalem in return for: (i) their own state in the West Bank and Gaza (taboo deal), (ii) their own state plus financial compensation (taboo+ deal), or (iii) their own state plus Israeli symbolically renouncing their sovereignty over the West Bank (symbolic deal).

After hearing the peace deal randomly assigned to them, participants were asked to nominate the, "feelings/emotions that come to mind when thinking about this deal". The choices were: humiliation, disgust, sadness, pride, anger, guilt, happiness, satisfaction or neutral. Participants were then given two indirect measures (to avoid posturing) of support and opposition to the peace deal. Our indirect measures were designed to take advantage of the false-consensus effect (Marks and Miller, 1987). The first measure asked participants to estimate the percentage of Palestinians who would vote for each deal, the second measure asked participants to estimate the percentage of Palestinians who would support a campaign of suicide bombings (in Scenario 1) or would martyr themselves (in Scenario 2) to oppose the deal. 
Results: Study $3 a$

For both scenarios we regressed support for the peace deals and for violent opposition to those deals respectively on whether participants expressed humiliation in response to the deals while controlling for gender, age, income, education levels, refugee status, area of residence (West Bank or Gaza) expressions of anger or disgust at the peace deal and identification with Hamas or Fatah. In Scenario 1 , participants who felt humiliated by the deal reported lower willingness to vote for it (humiliation first versus no humiliation, $B=-14.46, \mathrm{SE}=2.17, t=-6.65$, $P<0.0001$; humiliation second versus no humiliation, $B=-9.13, \mathrm{SE}=2.6, t=$ $-3.48, P=0.001$ ). Similar results were found for Scenario 2 (humiliation first versus no humiliation, $B=-10.28$, $\mathrm{SE}=2.03, t=-5.332, P<0.0001$; humiliation second versus no humiliation, $B=-2.825, \mathrm{SE}=2.22, t=-1.28, P=0.203$ ). Notably, experiences of humiliation were again unrelated to support for violent opposition to the peace deals (all not significant).

\section{Results: Study 36}

Here we investigated (i) whether symbolic gestures may increase positive attitudes towards peace deals and (ii) whether this effect would be mediated by fewer expressions of humiliation in response to the Israeli symbolic gesture. In Scenario 2, there was no reliable effect of experimental condition on predicted support for the deals. Thus we could only test the predicted mediation role of humiliation in Scenario 1. In Scenario 1, the mean percentage of Palestinians predicted to vote for deals was $38.26(\mathrm{SD}=24.91)$. Compared to the taboo condition, added material incentives to compromise in the taboo+ condition neither influenced predicted levels of support for the peace deal $(P=0.74)$ nor whether the deal was experienced as humiliating $(P=0.54)$. However, as predicted, symbolic Israeli compromises over Israeli sacred values resulted in increased Palestinian support for peace deals involving painful compromise over Palestinian sacred values, an effect that was mediated by a reduction in humiliation caused by the Israeli symbolic compromise (see Figure 1). Palestinians responding to the peace deal including the Israeli symbolic compromise were less likely, by a factor of 0.41 , to nominate humiliation as their first emotional response to the deal $(\mathrm{SE}=0.216$, Wald $=17.07, P<0.001)$ and showed greater support for the peace deal $(\mathrm{SE}=2.34, t=2.26, P=0.024)$. When support for the peace deal was simultaneously regressed on experimental condition and humiliation, experimental condition no longer significantly predicted support $(\mathrm{SE}=2.33, t=1.59, p>0.11)$, while humiliation negatively predicted support for the peace deal $(\mathrm{SE}=2.09, t=-4.36, P<0.0001$; Sobel test for mediation $=3.0, P=0.0027$ ). 


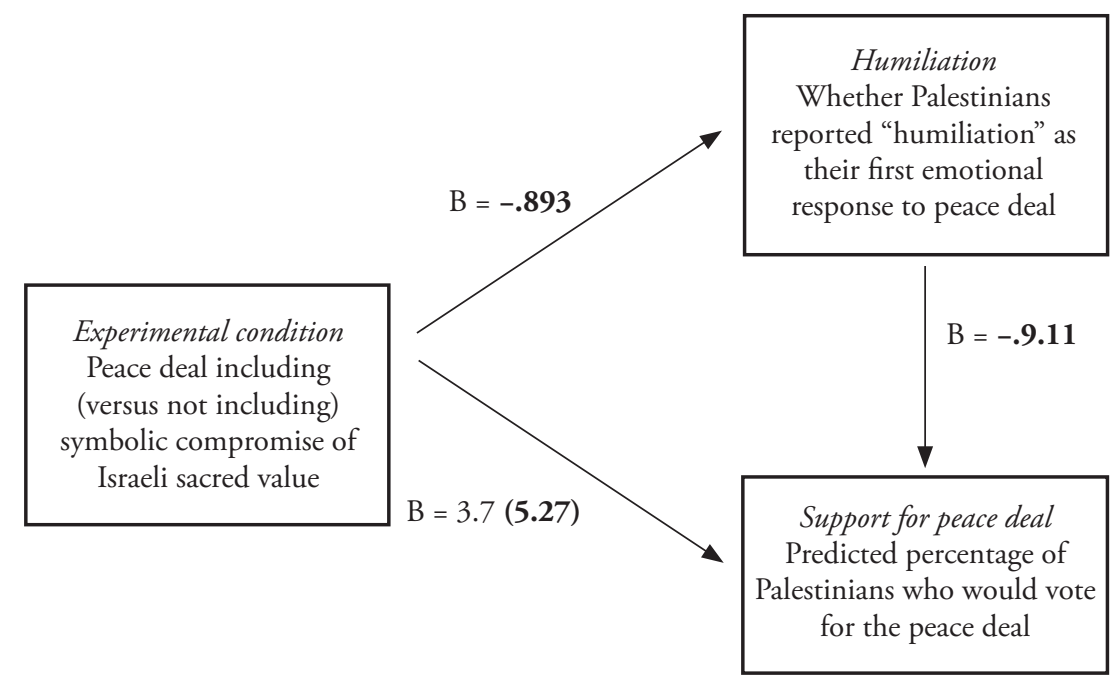

Figure 1. Test of the mediation hypothesis. All peace deals involved the same Palestinian compromise over their own sacred value in exchange for a twostate solution to the Israeli-Palestinian conflict.

\section{Summary}

Palestinians who felt humiliated by peace deals involving compromises over Palestinian sacred values showed less support for those deals, although they did not show greater support for violent opposition to those deals. In Scenario 1, a deal including a parallel Israeli compromise over one of their sacred values led to decreased feelings of humiliation which in turn caused increased support for the deal, while added instrumental benefits had no positive effect on willingness to accept compromise.

\section{Discussion}

We investigated the proposed inertia effect of humiliation and its influence on inter-group conflict. In studies that either measured or manipulated humiliating experiences of Palestinians in the context of the Israeli occupation, the experience of humiliation did not cause an increased propensity for violent reactions to the Israeli occupation. Instead, it led to apparent inertia: humiliation was typically negatively related to cognitive and emotional support for suicide attacks against Israelis and was never positively related to such support. 
It is interesting to juxtapose these empirical findings with reports of Palestinian and Islamic militants who frequently attribute their own actions to identity based experiences of humiliation. As is common in other domains where people do a poor job of understanding the cause of their own actions (Nisbett and Wilson, 1977), it appears that these self-attributions may be inaccurate. Possibly those involved in violent rebellion witness the frequent humiliation of others who they identify with, but experience this as either an insult or as threatened humiliation without internalizing the experience as humiliating (Khosrokhavar, 2006). In this way they avoid the inertia effect and instead respond with moral outrage and with a propensity for violence (Sageman, 2007). A related possibility is that there may be some type of "rebound" effect of humiliation: those who are humiliated may become less rebellious or violent, but if they are subsequently "empowered" by charismatic leaders or ideologies they might react with greater violence to avenge the insult of their previously humiliated state. Investigations of these possibilities may be a fruitful topic for future empirical research.

The inertia effect of humiliation also appears to suppress mutually beneficial inter-group compromise. Experiencing peace deals that involved compromise over a sacred value as humiliating decreased willingness to support these deals. Importantly, we found that feelings of humiliation caused by being asked to consider such peace deals were reduced, not by material incentives, but when the out-group made a simultaneous, parallel compromise over one of their own sacred values leading to increased support for the peace deal. This finding opens up a particularly intriguing and important line of future research focusing on two issues. First, what types of reciprocal symbolic compromises are necessary to reduce the humiliating effect of compromising sacred values? In this study we found that a combination of recognition and apology had a significant effect. We do not know whether this combination is necessary, or whether one of these aspects (e.g., apology) was sufficient. Second, we need to know more about the timing of symbolic gestures, whether they need to be simultaneous to be effective, or whether unilateral symbolic compromise might decrease the sense of humiliation felt by the other side, thus opening the way to peaceful conflict resolution.

Humiliation is an important feature of many inter-group conflicts, yet it has been a relatively neglected topic for empirical research. This study demonstrates that humiliation produces an inertia effect that, at least in the short term, dampens prospects of violent insurgency and also paradoxically reduces support for mutually beneficial compromises. Our findings demonstrate how a greater understanding of inertia effect may reveal methods for facilitating mutually beneficial compromises to a wide variety of inter-group conflicts. 


\section{Acknowledgements}

We thank Robert Axelrod, Brad Bushman, Doug Medin, Craig Joseph and Dan Bartels for their comments and suggestions. We thank Nadine Obeid and Patrycja Slawuta for their research assistance. This work was supported by National Science Foundation Grant SBE-0527396 and by grants from the Air Force Office of Scientific Research (AFOSR).

\section{References}

Atran, S. (2003). Genesis of suicide terrorism. Science 299, 1534-1539.

Atran, S. and Stern, J. (2005). Small groups find fatal purpose through the web. Nature 437, 620. Atran, S., Axelrod, R. and Davis, R. (2007). Sacred barriers to conflict resolution. Science 317, 1039-1040.

Bergen, P. and Lind, M. (2007). A matter or pride: Why we can't buy off the next Osama bin Laden. Democracy, A Journal Of Ideas 7, 8-16.

Bushman, B.J. and Baumeister, R.F. (1998). Threatened egotism, narcissism, self-esteem, and direct and displaced aggression: Does self-love or self-hate lead to violence? Journal of Personality and Social Psychology 75, 219-229.

Campbell, W.K., Bosson, J.K., Goheen, T.W., Lakey, C.E. and Kernis, M.H. (2007). Do narcissists dislike themselves "deep down inside"? Psychological Science 18, 227-229.

Campbell, W.K., Foster, J.D. and Brunell, A.B. (2004). Running From shame or reveling in pride? Narcissism and the regulation of self-conscious emotions. Psychological Inquiry 15, 150-153.

Coleman, P.T., Goldman, J.S. and Kugler, K. (2006). "Emotional Intractability: The effects of perceptions of emotional roles on immediate and delayed conflict outcomes". IACM 2006 Meetings Paper.

Ellyson, S.L. and Dovidio, J.F. (Eds) (1985). Power, dominance, and nonverbal behavior. Springer, New York, NY.

Fanon, F. (1967). The wretched of the earth. Penguin, Harmondsworth.

Fiske, S.T. (1993). Controlling other people: The impact of power on stereotyping. American Psychologist 48, 621-628.

Fontan, V. (2006). Polarization between occupier and occupied in post-Saddam Iraq: Colonial humiliation and the formation of political violence. Terrorism and Political Violence 18, 217-238.

Galinsky, A.D., Magee, J.C., Inesi, M.E. and Gruenfeld, D.H. (2006). Power and perspectives not taken. Psychological Science 17, 1068-1074.

Ginges, J. (1997). Deterring the terrorist: A psychological evaluation of different strategies for deterring terrorism. Terrorism and Political Violence 9, 170-185.

Ginges, J., Atran, S., Medin, D. and Shikaki, K. (2007). Sacred bounds on rational resolution of violent political conflict. Proceedings of the National Academy of Sciences of the United States of America 104, 7357-7360.

Hartling, L.M. and Luchetta, T. (1999). Humiliation: Assessing the impact of derision, degradation, and debasement. The Journal of Primary Prevention 19, 259-278.

Hassan, N. (2007) Suicide terrorism. In L. Richardson (ed.) The roots of terrorism. Routledge, New York, NY.

Holtgraves, T. and Lasky, B. (1999). Linguistic power and persuasion. Journal of Language and Social Psychology 18, 196-205. 
Juergensmeyer, M. (2000). Terror in the mind of God. University of California Press, Berkeley, CA. Keltner, D., Gruenfeld, D. and Anderson, C.P. (2003). Power, Approach, and Inhibition. Psychological Review 110, 265-284.

Keltner, D., Young, R. C., Heerey, E.A., Oemig, C. and Monarch, N.D. (1998). Teasing in hierarchical and intimate relations. Journal of Personality and Social Psychology 75, 1231-1247.

Khosrokhavar, F. (2006). Quand Al-Qaïda parle : Témoignages derrière les barreaux. Grasset, Paris.

Lindner, E.G. (2001). Humiliation and the human condition: Mapping a minefield. Human Rights Review 2, 46-63.

- (2002). Healing the cycles of humiliation: How to attend to the emotional aspects of "unsolvable" conflicts and the use of "humiliation entrepreneurship." Peace and Conflict: Journal of Psychology 8, 125-138.

Margalit, A. (2002). The ethics of memory. Harvard University Press, Cambridge, MA.

Marks, G. and Miller, N. (1987). Ten years of research on the false-consensus effect: An empirical and theoretical review. Psychological Bulletin 102, 72-90.

Moghadam, A. (2006). Suicide terrorism, occupation and the globalization of martyrdom: A critique of dying to win. Studies in Conflict and Terrorism 29, 707-729.

Moreland, R.L. and Levine, J.M. (1989). Newcomers and oldtimers in small groups. In P. Paulus (Ed.), Psychology of group influence. Lawrence Erlbaum, Hillsdale, NJ.

Newman, E. (2006). Exploring the "root causes" of terrorism. Studies in Conflict and Terrorism 29, 749-772.

Nisbett, R. and Cohen, D. (1996) Culture of honor: The psychology of violence in the South. Westview Press, Denver, CO.

Nisbett, R.E. and Wilson, T.D. (1977). Telling more than we can know: Verbal reports on mental processes. Psychological Review 84, 231-259.

Pew Research Center (2006). "America's image slips, but allies share U.S. concerns over Iran, Hamas" (Survey Report 13). Available online at http://pewglobal.org/reports/display.php?ReportID=252.

PHRMG (2006). Honor killing: killing of women and the basis for family honor. Palestinian Human Rights Monitor 6. Available online at www.phrmg.org/monitor2002/Aug2002-6.htm

Sageman, M. (2007). Leaderless Jihad. University of Pennsylvania Press, Philadelphia, PA.

Sen, A. (2006). Identity and violence. Norton, New York, NY.

Steinberg, B. (1991). Shame and Humiliation in the Cuban Missile Crisis: A psychoanalytic perspective. Political Psychology 12, 653-690.

Stern, J. (2003). Terror in the name of God: Why religious militants kill. Harper Collins, New York, NY.

Studd, M.V. (1996). Sexual harassment. In D.M. Buss and N.M. Malamuth (Eds), Sex, power, and conflict: Evolutionary and feminist perspectives. Oxford University Press, New York, NY.

Tangney, J.P. and Fischer, K.W. (Eds) (1995). Self-conscious emotions: The psychology of shame, guilt, embarrassment, and pride. Guilford Press, New York, NY.

Tetlock, P. (2003). Thinking the unthinkable: Sacred values and taboo cognitions. Trends in Cognitive Sciences 7, 320-324.

Victoroff, J. (2005). The mind of the terrorist: A review and critique of psychological approaches. Journal of Conflict Resolution 49, 3-42.

Wright, L. (2006). The Looming Tower. Alfred Knopf, New York, NY. 